\title{
Exigências de Proteína Bruta e Energia Metabolizável para Codornas Japonesas Criadas para a Produção de Carne ${ }^{1}$
}

\author{
Newton Tavares Escocard de Oliveira ${ }^{2}$, Martinho de Almeida e Silva ${ }^{3}$, Rita da Trindade Ribeiro \\ Nobre Soares ${ }^{4}$, José Brandão Fonseca ${ }^{5}$, José Tarcísio Lima Thiebaut ${ }^{6}$
}

RESUMO - Objetivando-se estimar as exigências de proteína bruta (PB) e energia metabolizável (EM) para máximo desempenho de codornas Japonesas de ambos os sexos, para a produção de carne, além de determinar a idade ótima de abate, 450 codornas de cada sexo, num total de 900 codornas, foram utilizadas em um delineamento experimental de blocos casualizados, com cinco repetições de seis codornas por unidade experimental. Os tratamentos foram constituídos do sexo das codornas e das dietas experimentais, resultantes das combinações de cinco níveis de PB (18, 20, 22, 24 e 26\%) e três níveis de EM $(2800,3000$ e $3200 \mathrm{kcal} / \mathrm{kg}$ de ração), e distribuídos nas parcelas e nos quatro períodos experimentais, como subparcelas. As exigências estimadas de PB e EM durante o primeiro (5 a 16), terceiro (27 a 38) e quarto (38 a 49 dias de idade) períodos foram: 26 e 2800, 18 e 3200 e 19,62\% e 3200 kcal $/ \mathrm{kg}$ ração para fêmeas e 26 e 2800,18 e 3200 e $18 \%$ e $3200 \mathrm{kcal} / \mathrm{kg}$ ração para machos, respectivamente. A exigência de PB para fêmeas e machos no segundo período ( 16 a 27 dias de idade) foi de $26 \%$, entretanto, não foi possível estimar a exigência de EM para ambos os sexos, em relação ao mesmo período. No período total, a exigência protéica estimada para ganho de peso máximo de fêmeas e machos foi de 24,73\%. As idades estimadas que resultaram em peso máximo dependeram do nível de PB da dieta, variando de 91 a 189 para fêmeas e de 57 a 83 dias para machos.

Palavras-chave: codornas japonesas, energia metabolizável, exigências nutricionais, idade de abate, proteína bruta

\section{Crude Protein and Metabolizable Energy Requirements for Japanese Quails Reared for Meat Production}

\begin{abstract}
Four hundred and fifty quails of each sex, in a total of nine hundred quails, were assigned to a completely randomized design with five replicates of six quails per experimental unit, to estimate the crude protein (CP) and metabolizable energy (ME) requirements for maximum performance of females and males Japanese quails reared for meat production purpose and to determine the best slaughter age. The treatments were consisted of the quails sex and the experimental diets, resultant from the combination of five levels of CP $(18,20,22,24$ and 26\%) and three level of ME $(2800,3000$ and $3200 \mathrm{kcal} / \mathrm{kg}$ of diet), and allotted to the plots and to the four experimental periods, as splitplots. The estimates of CP and ME requirements during the first (5 to 16), third (27 to 38) and fourth (38 to 49 days of age) periods were: 26 and 2800; 18 and 3200 and 19,62\% and $3200 \mathrm{kcal} / \mathrm{kg}$ of diet for females and 26 and $2800 ; 18$ and 3200 and $18 \%$ and $3200 \mathrm{kcal} / \mathrm{kg}$ of diet for males, respectively. The CP requirement for females and males in the second (16 to 27 days of age) period was $26 \%$, however it was not possible to estimate the ME requirement for both sexes, in relation to the same period. For the whole period, the estimated crude protein requirement for maximum weight gain of females and males was $24.73 \%$. The estimated ages for maximum body weight depended on the crude protein level of diet and varied from 91 to 189 days of age for females and from 57 to 83 days for males.
\end{abstract}

Key Words: crude protein, japanese quails, metabolizable energy, nutritional requirements, slaughter age

\section{Introdução}

A coturnicultura tem-se caracterizado como uma atividade que demanda baixos investimentos iniciais, uso de pequenas áreas e pequena necessidade de mão-de-obra. Aliado a estes atrativos, o ciclo reprodutivo curto com postura regular, a boa fertilidade e a precocidade sexual constituem as principais ca- racterísticas da codorna Japonesa (Coturnix coturnix japonica), tornando a produção de ovos o setor mais representativo da atividade.

Entretanto, em função da elevada taxa de crescimento e do consumo de ração reduzido, a criação de codornas de ambos os sexos para produção de carne pode constituir-se em nova alternativa para o setor avícola. Além disso, vale destacar que os machos

\footnotetext{
${ }^{1}$ Parte da tese de Mestrado apresentada pelo primeiro autor à UENF.

${ }^{2}$ Aluno de Pós-Graduação em Produção Animal do LZNA/CCTA/UENF. E.mail: newtonescocard@ig.com.br

${ }_{3}^{3}$ Professor do Departamento de Zootecnia/EV/UFMG. E.mail: martinho@vet.ufmg.br

${ }^{4}$ Professor do Laboratório de Zootecnia e Nutrição Animal/CCTA/UENF. E.mail: rnobre@uenf.br

${ }^{5}$ Professor do Laboratório de Zootecnia e Nutrição Animal/CCTA/UENF. E.mail: cppg@uenf.br

${ }^{6}$ Professor de Estatística do LZNA/CCTA/UENF. E.mail: jtt15@uenf.br
} 
descartados do sistema de produção de codornas Japonesas para produção de ovos têm tido custo de aquisição praticamente nulo.

Apesar do crescente e recente interesse na atividade, ainda são escassas as pesquisas sobre exigências nutricionais que alicerçam a formulação de rações de mínimo custo ou de máximo retorno, constituindo-se em um dos principais fatores que podem limitar a exploração comercial de codornas Japonesas para produção de carne. Somam-se a isso a falta de linhagens nacionais com características produtivas adequadas à produção de carne no ambiente tropical, a carência de pesquisas em processamento e embalagens que favoreçam a compra de carne de codorna e a ausência de divulgação da atividade e das qualidades da carne.

Fatores como genética, peso, idade, condições de alojamento da ave, balanço e disponibilidade de aminoácidos na dieta, entre outros, podem interferir nas exigências de proteína bruta e energia metabolizável de codornas Japonesas.

Tem-se verificado maior peso de codornas Japonesas quando alimentadas com dietas contendo $30 \%$ de proteína bruta, no período de 1 a 35 dias de idade (Kirkpinar \& Oguz, 1995), e codornas Japonesas alimentadas com $21,6 \%$ de proteína bruta têm tido maior taxa de crescimento no período de 22 a 35 dias de idade (Hyánková et al., 1997).

O nível de $2900 \mathrm{kcal} \mathrm{EM} / \mathrm{kg}$ de dieta tem sido recomendado para atender às exigências de codornas Japonesas em fase inicial e crescimento (NRC, 1994), embora codornas Japonesas não sexadas têm tido melhor conversão alimentar, quando alimentadas com dietas contendo 3000 do que $2800 \mathrm{kcal} \mathrm{EM} / \mathrm{kg}$ de dieta, no $42^{\circ}$ dia de idade (Murakami et al., 1993).

Assim, verifica-se a necessidade de se estabelecerem os níveis de proteína bruta e energia metabolizável para máximo desempenho de codornas Japonesas para corte, de ambos os sexos, em diversos períodos, além de determinar a idade ótima de abate.

\section{Material e Métodos}

O experimento foi realizado no Laboratório de Melhoramento Genético Animal do Centro de Ciências e Tecnologias Agropecuárias (CCTA) da Universidade Estadual do Norte Fluminense - UENF, localizada no município de Campos dos Goytacazes - RJ.

Foram utilizadas 900 codornas Japonesas (Coturnix coturnix japonica), sendo 450 fêmeas e
450 machos, em delineamento experimental de blocos inteiramente casualizados, com cinco repetições de seis codornas por unidade experimental. Os tratamentos, constituídos do sexo das codornas e das dietas experimentais, resultantes das combinações de cinco níveis de proteína bruta $(18,20,22,24$ e $26 \%$ ) e três níveis de energia metabolizável (2800, 3000 e $3200 \mathrm{kcal} / \mathrm{kg}$ de ração), foram distribuídos nas parcelas e nos quatro períodos experimentais $\left(5^{\circ}\right.$ ao $16^{\circ}, 16^{\circ}$ ao $27^{\circ}, 27^{\circ}$ ao $38^{\circ}$ e $38^{\circ}$ ao $49^{\circ}$ dia de idade), que constituíram as subparcelas. No período total $\left(5^{\circ}\right.$ ao $49^{\circ}$ dia de idade), utilizou-se o esquema fatorial $5 \times 3 \times 2$ sexos, obedecendo às mesmas combinações de níveis de fatores já citadas.

As codornas, com idade inicial de 5 dias, foram alojadas, por sexo, em galpão inicial contendo quatro gaiolas de madeira, com dimensão: $2 \mathrm{~m}$ de comprimento $x 0,52 \mathrm{~m}$ de largura $\mathrm{x} 0,15 \mathrm{~m}$ de altura, com 16 divisões internas cada e capacidade para 96 codornas por gaiola, onde permaneceram até o $27^{\circ}$ dia de idade.

A partir do $27^{\circ}$ dia de idade, as codornas foram transferidas para outro galpão e alojadas, por sexo, em gaiolas metálicas com dimensão: $1 \mathrm{~m}$ de comprimento x $0,34 \mathrm{~m}$ de largura x 0,24 m de altura, com quatro divisões internas cada, totalizando 24 codornas por gaiola, onde permaneceram até o $49^{\circ}$ dia de idade.

As codornas receberam água e ração à vontade, e 24 horas de luz diárias, seja natural ou artificial, a fim de incentivar o consumo.

As análises químicas foram realizadas no Laboratório de Zootecnia e Nutrição Animal (LZNA) e no Laboratório de Solos (LSOL), do Centro de Ciências e Tecnologias Agropecuárias - CCTA/UENF. A proteína bruta, o cálcio e o fósforo total analisados do milho, farelo de soja e farelo de trigo foram, respectivamente, $7,48,46,11$ e $14,43 \%$ de proteína bruta; $0,005,0,25$ e $0,11 \%$ de cálcio e $0,27,0,59$ e $1,13 \%$ de fósforo total.

A composição percentual das rações experimentais e os respectivos valores nutricionais calculados encontram-se na Tabela 1.

Exceto para proteína bruta, cálcio e fósforo, que foram analisados em laboratório, as dietas foram formuladas de acordo com as composições químicas dos ingredientes apresentadas por Rostagno et al. (1994) e adequadas às exigências nutricionais para codornas Japonesas do NRC (1994).

O fósforo disponível foi calculado a partir do fósforo total, considerando-se $33 \%$ a disponibilidade do mineral no milho, farelo de soja e farelo de trigo. 




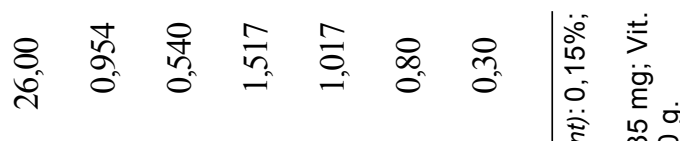

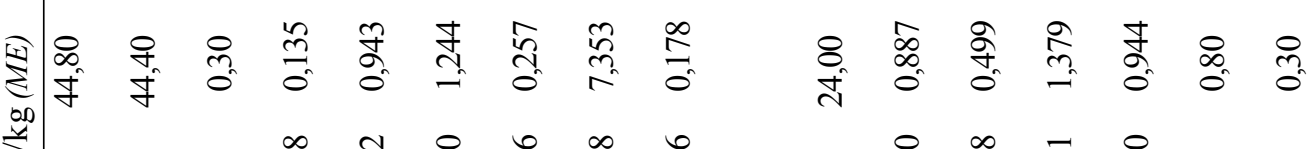

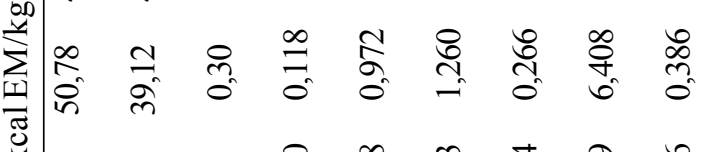

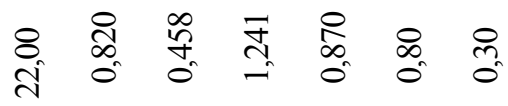

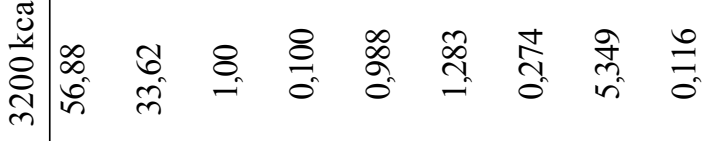

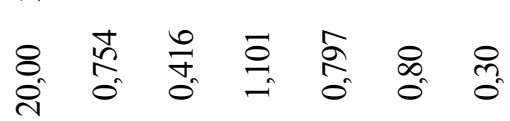

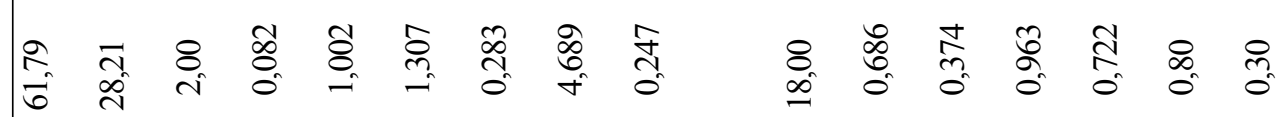

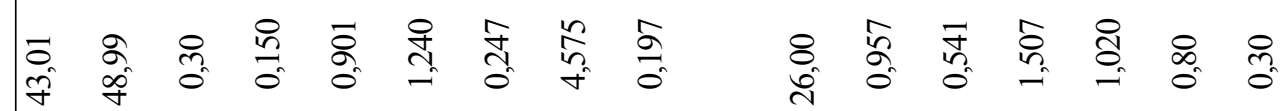

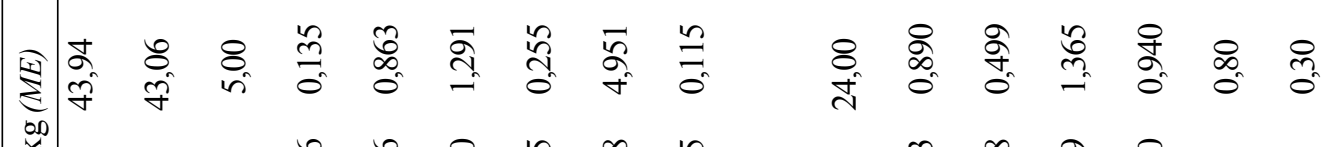
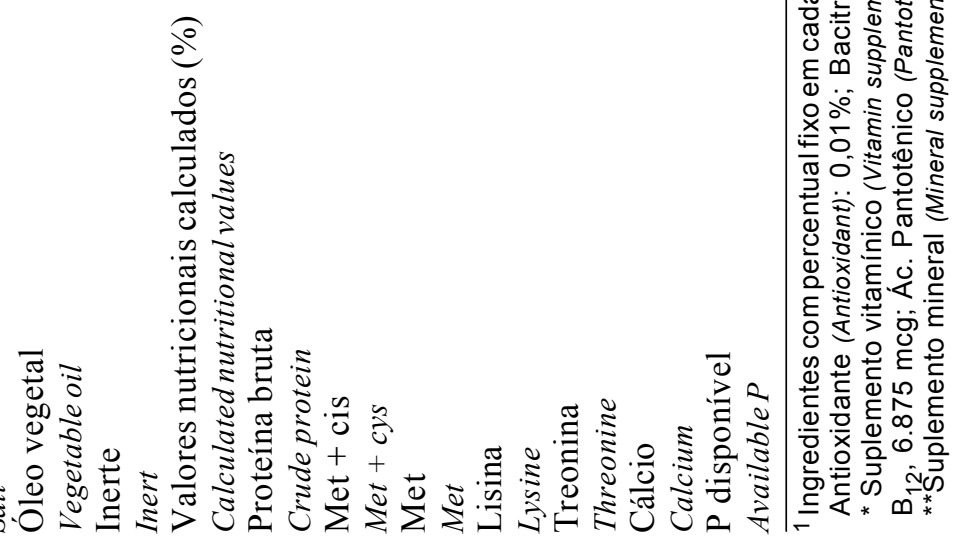
Os níveis de metionina, lisina e treonina foram calculados em torno de 2,$08 ; 5,42$; e $4,25 \%$ da proteína bruta das dietas, respectivamente, baseado nos valores apresentados pelo NRC (1994) (Tabela 1).

As variáveis avaliadas foram ganho de peso (GP), consumo de ração (CR) e conversão alimentar (CA) durante os quatro períodos experimentais, peso (P) no $5^{\circ}, 16^{\circ}, 27^{\circ}, 38^{\circ}$ e $49^{\circ}$ dia de idade e ganho de peso acumulado (GPA), consumo de ração acumulado (CRA) e conversão alimentar acumulada (CAA) no período total.

Os efeitos dos níveis de proteína bruta e dos níveis de energia metabolizável sobre as diversas variáveis foram estimados por meio de equações polinomiais, respeitando-se as suas interações significativas, porventura existentes, com os diversos fatores incluídos no modelo.

Foram também efetuadas regressões do peso das codornas em relação à idade, respeitadas as interações significativas entre idade e os demais fatores incluídos no modelo, para determinar a idade ótima de abate.

Todas as análises estatísticas foram efetuadas usando-se o programa SAEG (Sistema de análises estatísticas e genéticas), desenvolvido na Universidade Federal de Viçosa - UFV (1997).

\section{Resultados e Discussão}

Os resultados com relação às equações de regressão do consumo de ração (CR) em função dos níveis de energia metabolizável (EM), em cada combinação período e sexo, encontram-se na Tabela 2, na qual se constata que houve efeito linear negativo dos níveis de EM sobre o $\mathrm{CR}$, na maioria dos períodos experimentais, tanto para fêmeas quanto para machos. Nas combinações período e sexo, o nível $2800 \mathrm{kcal} \mathrm{EM} / \mathrm{kg}$ de ração promoveu maior CR das codornas. Houve efeito quadrático no quarto período com fêmeas, com consumo mínimo em $3116,67 \mathrm{kcal}$ $\mathrm{EM} / \mathrm{kg}$ de ração.

Angulo et al. (1993) relataram que o CR de codornas Japonesas alimentadas com dietas contendo $3000 \mathrm{kcal} \mathrm{EM} / \mathrm{kg}$ de ração foi maior que o daquelas alimentadas com $3200 \mathrm{kcal} \mathrm{EM} / \mathrm{kg}$ de ração, nos períodos de 1 a 14 e 14 a 33 dias de idade. Com base nestes dados, tem-se verificado maior CR de codornas Japonesas quando alimentadas com dietas contendo baixos níveis de EM, comparadas a aves alimentadas com maiores valores energéticos nas dietas.

Os resultados das médias do consumo de ração
Tabela 2 - Equações de regressão do consumo de ração ( $\mathrm{g}$ ) em função dos níveis de energia metabolizável (E), avaliadas em cada combinação período (T) e sexo (S)

Table 2 - Regressions of feed intake $(g)$ on metabolizable energy (E) levels for each period $(T)$ and sex (S) combination

\begin{tabular}{lll}
\hline $\mathrm{FV}$ & $\begin{array}{c}\text { Equações de regressão } \\
\text { Regression equations }\end{array}$ & $\mathrm{R}^{2}$ \\
\hline E/T1S1 & $\hat{\mathrm{Y}}=155,28-0,025 \mathrm{X}$ & 0,90 \\
E/T1S2 & $\hat{\mathrm{Y}}=165,25-0,029 \mathrm{X}$ & 0,97 \\
E/T2S1 & $\hat{\mathrm{Y}}=278,07-0,050 \mathrm{X}$ & 0,98 \\
E/T2S2 & $\hat{\mathrm{Y}}=252,97-0,042 \mathrm{X}$ & 0,94 \\
E/T3S1 & $\hat{\mathrm{Y}}=318,83-0,043 \mathrm{X}$ & 0,99 \\
E/T3S2 & $\hat{\mathrm{Y}}=258,40-0,031 \mathrm{X}$ & 0,83 \\
E/T4S1 & $\hat{\mathrm{Y}}=3085,09-1,87 \mathrm{X}+0,0003 \mathrm{X}^{2}$ & 1,00 \\
E/T4S2 & $\hat{\mathrm{Y}}=229,09-0,023 \mathrm{X}$ & 0,91 \\
\hline
\end{tabular}

$\mathrm{T} 1=5^{\circ}-16^{\circ}$ dia de idade $\left(T 1=5^{\text {th }}-16^{\text {th }}\right.$ day of age $)$.

$\mathrm{T} 2=16^{\circ}-27^{\circ}$ dia de idade $\left(T 2=16^{\text {th }}-27^{\text {th }}\right.$ day of age $)$.

$\mathrm{T} 3=27^{\circ}-38^{\circ}$ dia de idade $\left(T 3=27^{\text {th }}-38^{\text {th }}\right.$ day of age $)$.

$\mathrm{T} 4=38^{\circ}-49^{\circ}$ dia de idade $\left(T 4=38^{\text {th }}-49^{\text {th }}\right.$ day of age $)$.

S1 - Fêmeas (S1 - Females).

S2 - Machos (S2 - Males).

(CR) de fêmeas e machos, em cada combinação período e energia metabolizável (EM), encontram-se na Tabela 3. Não houve diferença entre os sexos em todos os níveis de energia metabolizável (EM) no primeiro e segundo períodos. Porém, no terceiro e quarto períodos, as fêmeas tiveram CR significativamente maior $(\mathrm{P} \leq 0,05)$ que os machos em cada nível de EM.

Os resultados referentes às equações de regressão do ganho de peso (GP), em função dos níveis de proteína bruta $(\mathrm{PB})$, em cada combinação período e sexo, estão apresentados na Tabela 4. O GP nos dois primeiros períodos, tanto para fêmeas quanto para machos, aumentou com os níveis de PB, indicando a influência sobre o desempenho das codornas nestes períodos. Os resultados mostraram que as codornas de ambos os sexos alimentadas com dietas contendo $26 \%$ de PB tiveram maior GP, sendo similares aos encontrados por Hyánková et al. (1997), que preconizaram $26 \%$ de $\mathrm{PB}$ para maior taxa de crescimento de fêmeas e machos de codornas Japonesas, no período de 1 a 21 dias de idade. Entretanto, o nível preconizado pelo NRC (1994) é de $24 \%$ de PB na dieta de codornas Japonesas em fase inicial/crescimento. Em trabalho de revisão, Shim \& Vohra (1984) citaram que Shim \& Lee (1982a) indicaram 24\%, Vogt (1967) recomendou 26\%, Lee et al. (1977a) recomendaram $28 \%$ até a terceira semana de idade 
Tabela 3 - Médias do consumo de ração (g/ave) em fêmeas e machos de codornas Japonesas, referentes a cada combinação período e energia metabolizável (EM)

Table 3 - Females and males Japanese quails average feed intake (g/bird), for each period and metabolizable energy (ME) combination

\begin{tabular}{|c|c|c|c|c|c|}
\hline \multirow[t]{2}{*}{$\begin{array}{l}\text { Sexo } \\
\text { Sex }\end{array}$} & \multirow[t]{2}{*}{$\begin{array}{l}\mathrm{EM}(\mathrm{kcal} / \mathrm{kg}) \\
M E(k c a l / k g)\end{array}$} & \multicolumn{4}{|c|}{$\begin{array}{l}\text { Períodos experimentais (dias de idade) } \\
\text { Experimental periods (days of age) }\end{array}$} \\
\hline & & $5^{\circ}-16^{\circ}$ & $16^{\circ}-27^{\circ}$ & $27^{\circ}-38^{\circ}$ & $38^{\circ}-49^{\circ}$ \\
\hline Fêmeas & 2800 & $86,11^{\mathrm{NS}}$ & $138,15^{\mathrm{NS}}$ & $198,55^{*}$ & $236,90^{*}$ \\
\hline $\begin{array}{l}\text { Females } \\
\text { Machos } \\
\text { Males }\end{array}$ & & 83,88 & 136,62 & 172,47 & 164,52 \\
\hline $\begin{array}{l}\text { Fêmeas } \\
\text { Females }\end{array}$ & 3000 & $78,22^{\mathrm{NS}}$ & $125,42^{\mathrm{NS}}$ & $188,07^{*}$ & $216,13 *$ \\
\hline $\begin{array}{l}\text { Machos } \\
\text { Males }\end{array}$ & & 76,20 & 124,61 & 161,34 & 162,51 \\
\hline $\begin{array}{l}\text { Fêmeas } \\
\text { Females }\end{array}$ & 3200 & $76,09^{\mathrm{NS}}$ & $118,03^{\mathrm{NS}}$ & $181,28^{*}$ & $219,72 *$ \\
\hline $\begin{array}{l}\text { Machos } \\
\text { Males }\end{array}$ & & 72,17 & 119,83 & 159,96 & 155,42 \\
\hline
\end{tabular}

* Significativo pelo teste $\mathrm{F}$ em nível de $5 \%$ de probabilidade.

NS - Não significativo $(P>0,05)$.

* Significant by $F$ test for probability level of $5 \%$.

NS Not significant $(P>$.05).

e Sakurai (1979) apontou 32,2\% de PB para o atendimento dos requerimentos de codornas Japonesas.

Houve decréscimo do GP no terceiro período experimental $\left(27^{\circ}\right.$ ao $38^{\circ}$ dia de idade) em machos com o aumento dos níveis de proteína bruta. Efeito quadrático dos níveis protéicos sobre o GP foi observado no quarto período $\left(38^{\circ}\right.$ ao $49^{\circ}$ dia de idade) em fêmeas, com ganho máximo no nível 19,62\% de PB (Tabela 4). Estes resultados mostram diminuição das exigências de $\mathrm{PB}$ em relação aos dois primeiros períodos. Resultados similares foram citados por Vohra (1971), mostrando que o nível de PB para fêmeas pode ser reduzido para $20 \%$ no período de três a seis semanas de idade.

Os resultados relativos às médias do GP estão apresentados na Tabela 5, na qual se observa que não houve diferença entre sexos em todos os níveis de proteína bruta $(\mathrm{PB})$ no primeiro período e nos níveis $18,22,24$ e $26 \%$ de PB no segundo período experimental. Contudo, as codornas fêmeas tiveram GP significativamente maior $(\mathrm{P} \leq 0,05)$ que machos em cada nível de PB no terceiro e quarto períodos, e no nível $20 \%$ de proteína no segundo período. Estes fatos são explicados pelos trabalhos de Farrell et al. (1982), em estudo com codornas Japonesas, e Du Preez \& Sales (1997), em codornas européias. Ambos os autores revelaram que a diferenciação de peso corporal entre sexos ocorre a partir da quarta semana de idade (coincide com o início do terceiro período experimental), possivelmente em função do maior crescimento dos órgãos reprodutivos das fêmeas.

Os resultados das equações de regressão do ganho de peso (GP) em relação aos níveis de proteína bruta (PB), em cada combinação período e energia metabolizável (EM), encontram-se na Tabela 6, na

Tabela 4 - Equações de regressão do ganho de peso (g), em função dos níveis de proteína bruta $(\mathrm{P})$, avaliadas em cada combinação período (T) e sexo (S)

Table 4 - Regressions of weight gain $(g)$ on crude protein $(P)$ levels for each period $(T)$ and sex $(S)$ combination

\begin{tabular}{llc}
\hline FV & $\begin{array}{c}\text { Equações de regressão } \\
\text { Regression equations }\end{array}$ & $\mathrm{R}^{2}$ \\
$S V$ & $\hat{\mathrm{Y}}=1,68+1,48 \mathrm{X}$ & \\
\hline $\mathrm{P} / \mathrm{T} 1 \mathrm{~S} 1$ & $\hat{\mathrm{Y}}=-0,89+1,54 \mathrm{X}$ & 0,99 \\
$\mathrm{P} / \mathrm{T} 1 \mathrm{~S} 2$ & $\hat{\mathrm{Y}}=26,96+0,82 \mathrm{X}$ & 0,99 \\
$\mathrm{P} / \mathrm{T} 2 \mathrm{~S} 1$ & $\hat{\mathrm{Y}}=25,15+0,81 \mathrm{X}$ & 0,92 \\
$\mathrm{P} / \mathrm{T} 2 \mathrm{~S} 2$ & - & 0,86 \\
$\mathrm{P} / \mathrm{T} 3 \mathrm{~S} 1$ & $\hat{\mathrm{Y}}=54,66-1,34 \mathrm{X}$ & - \\
$\mathrm{P} / \mathrm{T} 3 \mathrm{~S} 2$ & $\hat{\mathrm{Y}}=-63,50+9,42 \mathrm{X}-0,24 \mathrm{X}^{2}$ & 0,97 \\
$\mathrm{P} / \mathrm{T} 4 \mathrm{~S} 1$ & - & 0,87 \\
$\mathrm{P} / \mathrm{T} 4 \mathrm{~S} 2$ & & - \\
\hline
\end{tabular}

$\mathrm{T} 1=5^{\circ}-16^{\circ}$ dia de idade $\left(T 1=5^{\text {th }}-16^{\text {th }}\right.$ day of age $)$. $\mathrm{T} 2=16^{\circ}-27^{\circ}$ dia de idade $\left(T 2=16^{\text {th }}-27^{\text {th }}\right.$ day of age $)$.

$\mathrm{T} 3=27^{\circ}-38^{\circ}$ dia de idade $\left(T 3=27^{\text {th }}-38^{\text {th }}\right.$ day of age $)$.

$\mathrm{T} 4=38^{\circ}-49^{\circ}$ dia de idade $\left(T 4=38^{\text {th }}-49^{\text {th }}\right.$ day of age $)$.

S1 - Fêmeas (S1 - Females).

S2 - Machos (S2 - Males). 
Tabela 5 - Médias do ganho de peso (g/ave) em fêmeas e machos de codornas Japonesas, referentes a cada combinação período e proteína bruta

Table 5 - Female and male Japanese quails weight gain (g/bird) average for each period and crude protein level combination

\begin{tabular}{|c|c|c|c|c|c|c|}
\hline \multirow[t]{2}{*}{$\begin{array}{l}\text { Sexo } \\
\text { Sex }\end{array}$} & \multirow[t]{2}{*}{$\begin{array}{l}\text { Período (dias) } \\
\text { Period (days) }\end{array}$} & \multicolumn{5}{|c|}{$\begin{array}{c}\text { Níveis de proteína bruta (\%) } \\
\text { Crude protein levels (\%) }\end{array}$} \\
\hline & & 18 & 20 & 22 & 24 & 26 \\
\hline $\begin{array}{l}\text { Fêmeas } \\
\text { Females }\end{array}$ & $5^{0}-16^{0}$ & $28,86^{\mathrm{NS}}$ & $30,50^{\mathrm{NS}}$ & $34,36^{\mathrm{NS}}$ & $36,94^{\mathrm{NS}}$ & $40,43^{\mathrm{NS}}$ \\
\hline $\begin{array}{l}\text { Machos } \\
\text { Males }\end{array}$ & & 26,95 & 29,82 & 32,52 & 36,23 & 39,12 \\
\hline $\begin{array}{l}\text { Fêmeas } \\
\text { Females }\end{array}$ & $16^{0}-27^{o}$ & $40,94^{\mathrm{NS}}$ & $44,11^{*}$ & $45,69^{\mathrm{NS}}$ & $47,17^{\mathrm{NS}}$ & $47,67^{\mathrm{NS}}$ \\
\hline $\begin{array}{l}\text { Machos } \\
\text { Males }\end{array}$ & & 39,39 & 40,83 & 44,00 & 45,78 & 45,03 \\
\hline $\begin{array}{l}\text { Fêmeas } \\
\text { Females }\end{array}$ & $27^{\circ}-38^{\circ}$ & $44,22 *$ & $43,89 *$ & $45,87^{*}$ & $45,94^{*}$ & $44,33 *$ \\
\hline $\begin{array}{l}\text { Machos } \\
\text { Males }\end{array}$ & & 30,51 & 28,28 & 25,22 & 21,22 & 20,63 \\
\hline $\begin{array}{l}\text { Fêmeas } \\
\text { Females }\end{array}$ & $38^{\circ}-49^{\circ}$ & $27,15^{*}$ & $30,87^{*}$ & $25,05^{*}$ & $24,18^{*}$ & $18,68 *$ \\
\hline $\begin{array}{l}\text { Machos } \\
\text { Males }\end{array}$ & & 12,27 & 13,97 & 10,91 & 13,29 & 12,57 \\
\hline
\end{tabular}

* Significativo pelo teste $\mathrm{F}$ em nível de $5 \%$ de probabilidade.

NS - Não significativo $(P>0,05)$.

* Significant by $F$ test for probability level of $5 \%$.

NS Not significant $(P>.05)$

qual se nota que, com o aumento dos níveis de $\mathrm{PB}, \mathrm{o}$ GP foi crescente no primeiro $\left(5^{\circ}\right.$ ao $16^{\circ}$ dia de idade) e segundo $\left(16^{\circ}\right.$ ao $27^{\circ}$ dia de idade $)$ e decrescente no terceiro período, em todos os níveis de EM. Houve efeito quadrático dos níveis de PB sobre o GP, no nível $3200 \mathrm{kcal} \mathrm{EM} / \mathrm{kg}$ de ração no quarto período, com ganho máximo em 18,09\% de PB. Os resultados mostram que, embora avaliando sexos combinados, as exigências protéicas conservam-se num patamar mais elevado nos dois primeiros períodos, sendo reduzidas a partir do terceiro período experimental.

Os resultados das equações de regressão do GP, em função dos níveis de energia metabolizável (EM), em cada combinação período e proteína bruta (PB) estão na Tabela 7, e mostram que com o aumento dos níveis de EM, o GP foi decrescente no primeiro período, nos níveis 18,20 e $24 \%$ de PB. Nestas combinações período vs proteína, codornas alimentadas com dietas contendo $2800 \mathrm{kcal} \mathrm{EM} / \mathrm{kg}$ de ração tiveram maior GP. Begin (1968) não verificou diferença significativa em codornas Japonesas no período de 14 a 30 dias de idade, alimentadas com dietas contendo dois níveis de EM (3380 e $2180 \mathrm{kcal} / \mathrm{kg}$ de
Tabela 6 - Equações de regressão do ganho de peso (g), em função dos níveis de proteína bruta $(P)$, avaliadas em cada combinação período (T) e energia metabolizável (E)

Table 6 - Regressions of weight gain $(g)$ on crude protein $(P)$ levels for each period $(T)$ and metabolizable energy level (E) combination

\begin{tabular}{llc}
\hline FV & $\begin{array}{c}\text { Equações de regressão } \\
\text { Regression equations }\end{array}$ & $\mathrm{R}^{2}$ \\
\hline P/T1E1 & $\hat{\mathrm{Y}}=9,14+1,21 \mathrm{X}$ & 0,94 \\
P/T1E2 & $\hat{\mathrm{Y}}=1,03+1,48 \mathrm{X}$ & 0,89 \\
P/T1E3 & $\hat{\mathrm{Y}}=-9,00+1,83 \mathrm{X}$ & 0,98 \\
P/T2E1 & $\hat{\mathrm{Y}}=27,56+0,76 \mathrm{X}$ & 0,81 \\
P/T2E2 & $\hat{\mathrm{Y}}=29,75+0,65 \mathrm{X}$ & 0,91 \\
P/T2E3 & $\hat{\mathrm{Y}}=20,86+1,05 \mathrm{X}$ & 0,88 \\
P/T3E1 & $\hat{\mathrm{Y}}=48,02-0,68 \mathrm{X}$ & 0,88 \\
P/T3E2 & $\hat{\mathrm{Y}}=48,16-0,61 \mathrm{X}$ & 0,78 \\
P/T3E3 & $\hat{\mathrm{Y}}=49,35-0,55 \mathrm{X}$ & 0,72 \\
P/T4E1 & - & - \\
P/T4E2 & - & - \\
P/T4E3 & $\hat{\mathrm{Y}}=-36,34+6,73 \mathrm{X}-0,186 \mathrm{X}^{2}$ & 0,99 \\
\hline
\end{tabular}

$\mathrm{T} 1=5^{\circ}-16^{\circ}$ dia de idade $\left(T 1=5^{\text {th }}-16^{\text {th }}\right.$ day of age $)$.

$\mathrm{T} 2=16^{\circ}-27^{\circ}$ dia de idade $\left(T 2=16^{\text {th }}-27^{\text {th }}\right.$ day of age $)$.

$\mathrm{T} 3=27^{\circ}-38^{\circ}$ dia de idade $\left(T 3=27^{\text {th }}-38^{\text {th }}\right.$ day of age $)$.

$\mathrm{T} 4=38^{\circ}-49^{\circ}$ dia de idade ( $T 4=38^{\text {th }}-49^{\text {th }}$ day of age $)$.

$E 1-2800 \mathrm{kcal} / \mathrm{kg}$ de ração $(E 1=2800 \mathrm{kcal} / \mathrm{kg}$ of diet $)$.

$E 2-3000 \mathrm{kcal} / \mathrm{kg}$ de ração $(E 2=3000 \mathrm{kcal} / \mathrm{kg}$ of diet $)$.

E3 $-3200 \mathrm{kcal} / \mathrm{kg}$ de ração $(E 3=3200 \mathrm{kcal} / \mathrm{kg}$ of diet $)$. 
dieta), indicando que as mesmas não exigiram alta energia ou usaram melhor a baixa energia da dieta.

Com o aumento dos níveis energéticos, o GP foi crescente no terceiro e quarto períodos, nos níveis 18 , $22,24,26 \%$ e $18,22 \%$ de PB, respectivamente. Nestas combinações período e proteína, codornas alimentadas com dietas contendo $3200 \mathrm{kcal} \mathrm{EM} / \mathrm{kg}$ de ração tiveram maior GP. Efeito quadrático dos níveis energéticos sobre o GP ocorreu no primeiro e quarto períodos, nos níveis 22 e $26 \%$ de $\mathrm{PB}$, respectivamente. Os ganhos máximos aconteceram com codornas alimentadas com $3000 \mathrm{kcal} \mathrm{EM} / \mathrm{kg}$ de ração. O aumento da exigência energética de codornas Japonesas de ambos os sexos, entre o primeiro e os dois últimos períodos experimentais, pode estar relacionado com o aumento do tamanho corporal, além da

Tabela 7 - Equações de regressão do ganho de peso (g), em função dos níveis de energia metabolizável (E), avaliadas em cada combinação período $(T)$ e proteína bruta $(P)$

Table 7 - Regressions of weight gain $(g)$ on metabolizable energy $(E)$ levels for each period $(T)$ and crude protein $(P)$ combination

\begin{tabular}{lcc}
\hline $\mathrm{FV}$ & $\begin{array}{c}\text { Equações de regressão } \\
\text { Regression equations }\end{array}$ & $\mathrm{R}^{2}$ \\
SV & $\hat{\mathrm{Y}}=86,02-0,019 \mathrm{X}$ & 0,98 \\
\hline E/T1P1 & $\hat{\mathrm{Y}}=66,49-0,012 \mathrm{X}$ & 0,70 \\
E/T1P2 & $\hat{\mathrm{Y}}=-751,98+0,54 \mathrm{X}-0,00009 \mathrm{X}^{2}$ & 1,00 \\
E/T1P3 & - & 1,00 \\
E/T1P4 & $\hat{\mathrm{Y}}=68,30-0,011 \mathrm{X}$ & - \\
E/T1P5 & - & - \\
E/T2P1 & - & - \\
E/T2P2 & - & - \\
E/T2P3 & - & - \\
E/T2P4 & - & - \\
E/T2P5 & $\hat{\mathrm{Y}}=3,49+0,011 \mathrm{X}$ & 0,95 \\
E/T3P1 & - \\
E/T3P2 & $\hat{\mathrm{Y}}=1,15+0,011 \mathrm{X}$ & 0,72 \\
E/T3P3 & $\hat{\mathrm{Y}}=-0,80+0,011 \mathrm{X}$ & 0,78 \\
E/T3P4 & $\hat{\mathrm{Y}}=-4,14+0,012 \mathrm{X}$ & 0,86 \\
E/T3P5 & - & 0,95 \\
E/T4P1 & $\hat{\mathrm{Y}}=-49,64+0,023 \mathrm{X}$ & - \\
E/T4P2 & $\hat{\mathrm{Y}}=-39,98+0,019 \mathrm{X}$ & 0,94 \\
E/T4P3 & - & - \\
E/T4P4 & $\hat{\mathrm{Y}}=-1059,27+0,72 \mathrm{X}-0,00012 \mathrm{X}^{2}$ & 1,00 \\
E/T4P5 & &
\end{tabular}

$\mathrm{T} 1=5^{\circ}-16^{\circ}$ dia de idade $\left(T 1=5^{\text {th }}-16^{\text {th }}\right.$ day of age $)$.

$\mathrm{T} 2=16^{\circ}-27^{\circ}$ dia de idade $\left(T 2=16^{\text {th }}-27^{\text {th }}\right.$ day of age $)$.

$\mathrm{T} 3=27^{\circ}-38^{\circ}$ dia de idade $\left(T 3=27^{\text {th }}-38^{\text {th }}\right.$ day of age $)$.

$\mathrm{T} 4=38^{\circ}-49^{\circ}$ dia de idade $\left(T 4=38^{\text {th }}-49^{\text {th }}\right.$ day of age $)$.

$\mathrm{P} 1-18 \%$ de proteína bruta $(P 1=18 \%$ of crude protein).

P2 $-20 \%$ de proteína bruta $(P 2=20 \%$ of crude protein)

P3 $-22 \%$ de proteína bruta $(P 3=22 \%$ of crude protein).

P4 $-24 \%$ de proteína bruta ( $P 4=24 \%$ of crude protein).

P5 - $26 \%$ de proteína bruta ( $P 5=26 \%$ of crude protein). maior demanda energética metabólica das fêmeas, em função do estado fisiológico.

Os resultados das médias de conversão alimentar (CA) nos dois sexos (Tabela 8) indicam que não houve diferença entre sexos em todos os níveis de proteína bruta $(\mathrm{PB})$ no primeiro e segundo períodos e nos níveis 18,20 e $26 \%$ de $\mathrm{PB}$, no terceiro e quarto períodos, respectivamente. Entretanto, as codornas fêmeas tiveram CA significativamente maior $(\mathrm{P} \leq 0,05)$ que machos, nos níveis $22,24,26 \%$ e $18,20,22,24 \%$ de $\mathrm{PB}$, no terceiro e quarto períodos, respectivamente. Exceto quanto aos níveis $20 \%$ no segundo, 18 e $20 \%$ no terceiro e $26 \%$ de PB no quarto período, estes resultados coincidem com os obtidos com o GP.

Os resultados em relação às equações de regressão do peso $(\mathrm{P})$ em função de idade, em cada combinação proteína e sexo, estão apresentados na Tabela 9. Observou-se efeito linear positivo de idade sobre o $\mathrm{P}$ nos níveis 18 e $20 \%$ e efeito quadrático nos níveis 22 $(\mathrm{P}$ máximo $=189$ dias $), 24(\mathrm{P}$ máximo $=141$ dias $) \mathrm{e}$ $26 \%$ de proteína bruta $(\mathrm{P}$ máximo $=91$ dias $)$, em fêmeas. Efeito quadrático de idade sobre o $\mathrm{P}$ foi observado em todos os níveis protéicos em machos, com P máximo, em ordem crescente de nível protéico, igual a $83,79,63,59$ e 57 dias, respectivamente.

Os resultados das médias do $\mathrm{P}$ de cada sexo, em cada combinação idade e proteína bruta (PB), encontram-se apresentados na Tabela 10 , na qual se constata que as codornas fêmeas e machos obtiveram pesos semelhantes $(\mathrm{P}>0,05)$ em todos os níveis de $\mathrm{PB}$ nas idades de 5 e 16 dias e nos níveis 22 e $24 \%$ de PB, aos 27 dias. As fêmeas foram significativamente $(\mathrm{P} \leq 0,05)$ mais pesadas que machos nos níveis 18,20 e $26 \%$ de $\mathrm{PB}$ aos 27 dias e em todos os níveis de $\mathrm{PB}$ nas idades de 38 e 49 dias.

Os resultados referentes às equações de regressão do consumo de ração acumulado (CRA) em função dos níveis de energia metabolizável (EM), em cada combinação proteína bruta (PB) e sexo, encontram-se apresentados na Tabela 11. Observa-se que houve efeito quadrático dos níveis de EM sobre o CRA, nos níveis 26 (CRA mínimo em 3168 kcal EM/ $\mathrm{kg}$ de ração) e 18\% de PB (CRA mínimo em 3023 $\mathrm{kcal} \mathrm{EM} / \mathrm{kg}$ de ração), em fêmeas e machos, respectivamente. Verificou-se efeito linear negativo dos níveis de EM sobre o CRA nos níveis 18, 20, 22 e 24\% em fêmeas e nos níveis 20, 22, 24 e $26 \%$ de PB em machos. Nestas combinações proteína e sexo, as fêmeas e machos alimentados com dietas contendo $2800 \mathrm{kcal} \mathrm{EM} / \mathrm{kg}$ de ração tiveram maior CRA. 
Tabela 8 - Médias da conversão alimentar em fêmeas e machos de codornas Japonesas, referentes a cada combinação período e proteína bruta

Table 8 - Females and males Japanese quail average feed:gain ratio for each period and crude protein combination

\begin{tabular}{|c|c|c|c|c|c|c|}
\hline \multirow[t]{2}{*}{$\begin{array}{l}\text { Sexo } \\
\text { Sex }\end{array}$} & \multirow[t]{2}{*}{$\begin{array}{l}\text { Período (dias) } \\
\text { Period (days) }\end{array}$} & \multicolumn{5}{|c|}{$\begin{array}{l}\text { Níveis de proteína bruta (\%) } \\
\text { Crude protein levels (\%) }\end{array}$} \\
\hline & & 18 & 20 & 22 & 24 & 26 \\
\hline $\begin{array}{l}\text { Fêmeas } \\
\text { Females }\end{array}$ & $5^{\circ}-16^{\circ}$ & $2,73^{\mathrm{NS}}$ & $2,55^{\mathrm{NS}}$ & $2,32^{\mathrm{NS}}$ & $2,31^{\mathrm{NS}}$ & $2,06^{\mathrm{NS}}$ \\
\hline $\begin{array}{l}\text { Machos } \\
\text { Males }\end{array}$ & & 2,73 & 2,63 & 2,35 & 2,19 & 2,06 \\
\hline $\begin{array}{l}\text { Fêmeas } \\
\text { Females }\end{array}$ & $16^{\circ}-27^{\circ}$ & $2,99^{\mathrm{NS}}$ & $2,86^{\mathrm{NS}}$ & $2,76^{\mathrm{NS}}$ & $2,74^{\mathrm{NS}}$ & $2,79^{\mathrm{NS}}$ \\
\hline $\begin{array}{l}\text { Machos } \\
\text { Males }\end{array}$ & & 3,06 & 3,12 & 2,88 & 2,91 & 2,88 \\
\hline $\begin{array}{l}\text { Fêmeas } \\
\text { Females }\end{array}$ & $27^{\circ}-38^{\circ}$ & $4,27^{\mathrm{NS}}$ & $4,24^{\mathrm{NS}}$ & $4,04^{*}$ & $4,34^{*}$ & $4,43^{*}$ \\
\hline $\begin{array}{l}\text { Machos } \\
\text { Males }\end{array}$ & & 5,32 & 6,11 & 6,79 & 8,11 & 8,26 \\
\hline $\begin{array}{l}\text { Fêmeas } \\
\text { Females }\end{array}$ & $38^{\circ}-49^{\circ}$ & $8,49^{*}$ & $7,20^{*}$ & $10,44^{*}$ & $10,31^{*}$ & $14,61^{\mathrm{NS}}$ \\
\hline $\begin{array}{l}\text { Machos } \\
\text { Males }\end{array}$ & & 14,38 & 12,99 & 21,71 & 13,72 & 13,97 \\
\hline
\end{tabular}

* Significativo pelo teste $\mathrm{F}$ em nível de $5 \%$ de probabilidade.

NS - Não significativo $(P>0,05)$.

* Significant by $\mathrm{F}$ test for probability level of $5 \%$.

NS Not significant $(P>$.05)

Resultados semelhantes foram obtidos por Murakami et al. (1993), que observaram maior CRA de codornas Japonesas submetidas a dietas com $2800 \mathrm{kcal}$ $\mathrm{EM} / \mathrm{kg}$ de ração, comparadas àquelas que receberam $3000 \mathrm{kcal} \mathrm{EM} / \mathrm{kg}$ de ração, no período de 1 a 42 de idade, e por Angulo et al. (1993), quando utilizaram dietas contendo 3000 e $3200 \mathrm{kcal} \mathrm{EM} / \mathrm{kg}$ de ração e considerando o período de 1 a 33 dias de idade.

As médias do CRA de cada sexo, em cada combinação proteína bruta (PB) e energia metabolizável (EM), constam na Tabela 12. Nota-se que as fêmeas consumiram significativamente $(\mathrm{P} \leq 0,05)$

Tabela 9 - Equações de regressão do peso (g), em função de idade (I), avaliadas em cada combinação proteína bruta (P) e sexo (S)

Table 9 - Regressions of body weight $(g)$ on age (I) for each crude protein $(P)$ and sex (S) combination

\begin{tabular}{llcc}
\hline FV & $\begin{array}{c}\text { Equações de regressão } \\
\text { Regression equations }\end{array}$ & $\mathrm{R}^{2}$ & $\begin{array}{c}\text { Ponto máximo(dias) } \\
\text { Maximum point (days) }\end{array}$ \\
\hline I/P1S1 & $\hat{\mathrm{Y}}=-4,13+3,34 \mathrm{X}$ & 0,99 & - \\
$\mathrm{I} / \mathrm{P} 1 \mathrm{~S} 2$ & $\hat{\mathrm{Y}}=-7,65+3,84 \mathrm{X}-0,023 \mathrm{X}^{2}$ & 0,99 & 83 \\
$\mathrm{I} / \mathrm{P} 2 \mathrm{~S} 1$ & $\hat{\mathrm{Y}}=-5,61+3,52 \mathrm{X}$ & 0,99 & - \\
$\mathrm{I} / \mathrm{P} 2 \mathrm{~S} 2$ & $\hat{\mathrm{Y}}=-7,58+4,09 \mathrm{X}-0,026 \mathrm{X}^{2}$ & 0,99 & 79 \\
I/P3S1 & $\hat{\mathrm{Y}}=-9,43+4,16 \mathrm{X}-0,011 \mathrm{X}^{2}$ & 0,99 & 189 \\
$\mathrm{I} / \mathrm{P} 3 \mathrm{~S} 2$ & $\hat{\mathrm{Y}}=-10,90+4,65 \mathrm{X}-0,037 \mathrm{X}^{2}$ & 0,99 & 63 \\
I/P4S1 & $\hat{\mathrm{Y}}=-10,80+4,50 \mathrm{X}-0,016 \mathrm{X}^{2}$ & 0,99 & 141 \\
$\mathrm{I} / \mathrm{P} 4 \mathrm{~S} 2$ & $\hat{\mathrm{Y}}=-11,87+4,97 \mathrm{X}-0,042 \mathrm{X}^{2}$ & 0,99 & 59 \\
I/P5S1 & $\hat{\mathrm{Y}}=-13,41+5,08 \mathrm{X}-0,028 \mathrm{X}^{2}$ & 0,99 & 91 \\
I/P5S2 & $\hat{\mathrm{Y}}=-12,55+5,20 \mathrm{X}-0,046 \mathrm{X}^{2}$ & 0,99 & 57 \\
\hline
\end{tabular}

$\mathrm{P} 1-18 \%$ de proteína bruta $(P 1=18 \%$ of crude protein $)$.

P2 $-20 \%$ de proteína bruta ( $P 2=20 \%$ of crude protein).

P3 $-22 \%$ de proteína bruta ( $P 3=22 \%$ of crude protein).

P4 $-24 \%$ de proteína bruta ( $P 4=24 \%$ of crude protein).

P5 $-26 \%$ de proteína bruta ( $P 5=26 \%$ of crude protein).

S1 - Fêmeas (S1 - Females).

S2 - Machos (S2 - Males). 
Tabela 10 - Médias do peso (g/ave) em fêmeas e machos de codornas Japonesas, referentes a cada combinação idade e proteína bruta

Table 10 - Female and male Japanese quails body weight (g/bird) average for each age and crude protein combination

\begin{tabular}{|c|c|c|c|c|c|c|}
\hline \multirow[t]{2}{*}{$\begin{array}{l}\text { Sexo } \\
\text { Sex }\end{array}$} & \multirow[t]{2}{*}{$\begin{array}{c}\text { Idades (dias) } \\
\text { Age (days) }\end{array}$} & \multicolumn{5}{|c|}{$\begin{array}{l}\text { Níveis de proteína bruta (\%) } \\
\text { Crude protein levels (\%) }\end{array}$} \\
\hline & & 18 & 20 & 22 & 24 & 26 \\
\hline $\begin{array}{l}\text { Fêmeas } \\
\text { Females }\end{array}$ & 5 & $15,30^{\mathrm{NS}}$ & $14,73^{\mathrm{NS}}$ & $14,20^{\mathrm{NS}}$ & $14,39^{\mathrm{NS}}$ & $14,40^{\mathrm{NS}}$ \\
\hline $\begin{array}{l}\text { Machos } \\
\text { Males }\end{array}$ & & 14,21 & 15,07 & 14,53 & 14,43 & 14,38 \\
\hline $\begin{array}{l}\text { Fêmeas } \\
\text { Females }\end{array}$ & 16 & $44,17^{\mathrm{NS}}$ & $45,22^{\mathrm{NS}}$ & $48,56^{\mathrm{NS}}$ & $51,33^{\mathrm{NS}}$ & $54,83^{\mathrm{NS}}$ \\
\hline $\begin{array}{l}\text { Machos } \\
\text { Males }\end{array}$ & & 41,17 & 44,89 & 47,05 & 50,67 & 53,50 \\
\hline $\begin{array}{l}\text { Fêmeas } \\
\text { Females }\end{array}$ & 27 & $85,11 *$ & $89,33 *$ & $94,24^{\mathrm{NS}}$ & $98,50^{\mathrm{NS}}$ & $102,50 *$ \\
\hline $\begin{array}{l}\text { Machos } \\
\text { Males }\end{array}$ & & 80,56 & 85,72 & 91,05 & 96,44 & 98,53 \\
\hline $\begin{array}{l}\text { Fêmeas } \\
\text { Females }\end{array}$ & 38 & $129,33^{*}$ & $133,22 *$ & $140,11^{*}$ & $144,44^{*}$ & $146,83^{*}$ \\
\hline $\begin{array}{l}\text { Machos } \\
\text { Males }\end{array}$ & & 111,07 & 114,00 & 116,28 & 117,67 & 119,17 \\
\hline $\begin{array}{l}\text { Fêmeas } \\
\text { Females }\end{array}$ & 49 & $156,48^{*}$ & $164,09 *$ & $165,17 *$ & $168,63^{*}$ & $165,52 *$ \\
\hline $\begin{array}{l}\text { Machos } \\
\text { Males }\end{array}$ & & 123,34 & 127,97 & 127,19 & 130,95 & 131,74 \\
\hline
\end{tabular}

* Significativo pelo teste $\mathrm{F}$ em nível de $5 \%$ de probabilidade.

NS - Não significativo $(P>0,05)$.

* Significant by $F$ test for probability level of $5 \%$.

NS Not significant $(P>.05)$.

Tabela 11 - Equações de regressão do consumo de ração acumulado (g), em função dos níveis de energia metabolizável $(E)$, avaliadas em cada combinação proteína bruta $(P)$ e sexo (S)

Table 11 - Regressions of total feed intake $(g)$ on metabolizable energy levels $(E)$ for each crude protein $(P)$ and sex $(S)$ combination

\begin{tabular}{llcc}
\hline FV & $\begin{array}{c}\text { Equações de regressão } \\
\text { Regression equations }\end{array}$ & $\mathrm{R}^{2}$ & $\begin{array}{c}\text { Ponto mínimo(dias) } \\
\text { Minimum point (days) }\end{array}$ \\
\hline E/P1S1 & $\hat{\mathrm{Y}}=1344,92-0,25 \mathrm{X}$ & 0,99 & - \\
E/P1S2 & $\hat{\mathrm{Y}}=8533,82-5,32 \mathrm{X}+0,00088 \mathrm{X}^{2}$ & 1,00 & 3023 \\
E/P2S1 & $\hat{\mathrm{Y}}=983,96-0,13 \mathrm{X}$ & 0,74 & - \\
E/P2S2 & $\hat{\mathrm{Y}}=1026,08-0,16 \mathrm{X}$ & 0,87 & - \\
E/P3S1 & $\hat{\mathrm{Y}}=1013,53-0,13 \mathrm{X}$ & 0,98 & - \\
E/P3S2 & $\hat{\mathrm{Y}}=854,07-0,11 \mathrm{X}$ & 0,81 & - \\
E/P4S1 & $\hat{\mathrm{Y}}=1337,19-0,23 \mathrm{X}$ & 0,97 & - \\
E/P4S2 & $\hat{\mathrm{Y}}=1022,77-0,16 \mathrm{X}$ & 0,94 & - \\
E/P5S1 & $\hat{\mathrm{Y}}=11166,60-6,97 \mathrm{X}+0,0011 \mathrm{X}^{2}$ & 1,00 & 3168 \\
E/P5S2 & $\hat{\mathrm{Y}}=992,14-0,15 \mathrm{X}$ & 0,94 & - \\
\hline
\end{tabular}

$\mathrm{P} 1-18 \%$ de proteína bruta $(P 1=18 \%$ of crude protein).

P2 $-20 \%$ de proteína bruta $(P 2=20 \%$ of crude protein).

P3 $-22 \%$ de proteína bruta $(P 3=22 \%$ of crude protein).

P4 $-24 \%$ de proteína bruta ( $P 4=24 \%$ of crude protein).

P5 $-26 \%$ de proteína bruta ( $P 5=26 \%$ of crude protein).

S1 - Fêmeas (S1 - Females).

S2 - Machos (S2 - Males). 
mais ração que machos, em todas as combinações de níveis de PB e EM.

Observou-se efeito quadrático dos níveis de proteína bruta $(\mathrm{PB})$ sobre o ganho de peso acumulado (GPA), independentemente dos níveis de EM e do fator sexo. O ganho máximo ocorreu no nível $24,73 \%$ de $\mathrm{PB}$, obtido pela equação $\hat{\mathrm{Y}}=10,35+$ $10,04 \mathrm{X}-0,203 \mathrm{X}^{2}$, com médias (g/ave) iguais a: $18 \%-125,15 ; 20 \%-131,13 ; 22 \%-131,81 ; 24 \%$ 135,38 e $26 \%$ - 134,24. Este resultado está acima do recomendado pelo NRC (1994), que sugere $24 \%$ de $\mathrm{PB}$ para atender às exigências de codornas em fase inicial/crescimento, porém Sinha \& Verma (1984) concluíram que não houve efeito significativo $(\mathrm{P}>0,05)$ dos níveis de PB sobre o GPA de codornas Japonesas de ambos os sexos, alimentadas com dietas contendo 24,26 e $28 \%$ de $\mathrm{PB}$, do $7^{\circ}$ ao $49^{\circ}$ dia de idade e Marks (1978) revelou que o GPA de codornas Japonesas de ambos os sexos alimentadas com dietas contendo $20 \%$ de $\mathrm{PB}$, no período de duas a seis semanas de idade, foi $96 \%$ menor que codornas alimentadas com $28 \%$ de PB no mesmo período.

As fêmeas tiveram GPA significativamente $(P \leq 0,05)$ maior que os machos, independentemente dos níveis de PB e EM, sendo as médias para fêmeas $149,37 \mathrm{~g}$ e para os machos $113,71 \mathrm{~g}$.

Os resultados das equações de regressão da conversão alimentar acumulada (CAA) em função do níveis de EM, em cada combinação PB e sexo, encontram-se na Tabela 13 , na qual se observou efeito linear negativo dos níveis de EM sobre a CAA nos níveis 18, 22 e $24 \%$ em fêmeas e $20,22,24$ e $26 \%$ de PB em machos, mostrando que as codornas alimentadas com dietas contendo $3200 \mathrm{kcal} \mathrm{EM} / \mathrm{kg}$ de ração obtiveram melhor CAA, nestas combinações $\mathrm{PB}$ e sexo. Houve efeito quadrático dos níveis de EM sobre a CAA, no nível 26\% (CAA mínima em $3034 \mathrm{kcal} \mathrm{EM} / \mathrm{kg}$ de ração) em fêmeas e $18 \%$ de PB (CAA mínima em $3086 \mathrm{kcal} \mathrm{EM} / \mathrm{kg}$ de ração) em machos.

As médias da CAA de fêmeas e machos, em cada combinação proteína bruta (PB) e energia metabolizável (EM), encontram-se apresentadas na Tabela 14. As fêmeas tiveram melhor CAA $(\mathrm{P} \leq 0,05)$ que machos em todas as combinações de níveis de PB e EM, exceto nas combinações 18/3000, 26/2800 e $26 / 3200$.

Tabela 12 - Médias do consumo de ração acumulado (g/ave) em fêmeas e machos de codornas Japonesas, referentes a cada combinação proteína bruta e energia metabolizável (EM)

Table 12 - Female and male Japanese quails total feed intake (g/bird) average for each crude protein and metabolizable energy (ME) combination

\begin{tabular}{|c|c|c|c|c|c|c|}
\hline \multirow[t]{2}{*}{$\begin{array}{l}\text { Sexo } \\
\text { Sex }\end{array}$} & \multirow[t]{2}{*}{$\begin{array}{c}\mathrm{EM}(\mathrm{kcal} / \mathrm{kg}) \\
M E(\mathrm{kcal} / \mathrm{kg})\end{array}$} & \multicolumn{5}{|c|}{$\begin{array}{l}\text { Níveis de proteína bruta }(\%) \\
\text { Crude protein levels }(\%)\end{array}$} \\
\hline & & 18 & 20 & 22 & 24 & 26 \\
\hline Fêmeas & 2800 & $646,23 *$ & $638,60 *$ & $641,48^{*}$ & $697,29 *$ & $675,01 *$ \\
\hline Females & & & & & & \\
\hline $\begin{array}{l}\text { Machos } \\
\text { Males }\end{array}$ & & 528,02 & 578,82 & 543,71 & 580,29 & 556,60 \\
\hline $\begin{array}{l}\text { Fêmeas } \\
\text { Females }\end{array}$ & 3000 & $591,58^{*}$ & $587,04 *$ & $607,93 *$ & $637,09 *$ & $615,59 *$ \\
\hline $\begin{array}{l}\text { Machos } \\
\text { Males }\end{array}$ & & 484,43 & 524,89 & 540,43 & 534,18 & 539,37 \\
\hline $\begin{array}{l}\text { Fêmeas } \\
\text { Females }\end{array}$ & 3200 & $546,20^{*}$ & $588,01 *$ & $588,00 *$ & $605,21 *$ & $648,17 *$ \\
\hline $\begin{array}{l}\text { Machos } \\
\text { Males }\end{array}$ & & 511,27 & 513,91 & 500,25 & 516,40 & 495,02 \\
\hline
\end{tabular}

* Significativo pelo teste $\mathrm{F}$ em nível $5 \%$ de probabilidade.

* Significant by $F$ test for probability level of $5 \%$. 
Tabela 13 - Equações de regressão da conversão alimentar acumulada, em função dos níveis de energia metabolizável $(E)$, avaliadas em cada combinação proteína bruta $(P)$ e sexo $(S)$

Table 13 - Regressions of total feed:gain ratio on metabolizable energy $(E)$ level for each crude protein $(P)$ and sex $(S)$ combination

\begin{tabular}{llcc}
\hline FV & $\begin{array}{c}\text { Equações de regressão } \\
\text { Regression equations }\end{array}$ & $\mathrm{R}^{2}$ & $\begin{array}{c}\text { Ponto mínimo(dias) } \\
\text { Minimum point(days) }\end{array}$ \\
\hline E/P1S1 & $\hat{\mathrm{Y}}=9,54-0,0018 \mathrm{X}$ & 0,99 & - \\
E/P1S2 & $\hat{\mathrm{Y}}=80,50-0,05 \mathrm{X}+0,0000081 \mathrm{X}^{2}$ & 1,00 & 3086 \\
E/P2S1 & - & - & - \\
E/P2S2 & $\hat{\mathrm{Y}}=9,59-0,0016 \mathrm{X}$ & 0,95 & - \\
E/P3S1 & $\hat{\mathrm{Y}}=8,69-0,0015 \mathrm{X}$ & 0,97 & - \\
E/P3S2 & $\hat{\mathrm{Y}}=10,54-0,0019 \mathrm{X}$ & 0,99 & - \\
E/P4S1 & $\hat{\mathrm{Y}}=8,17-0,0013 \mathrm{X}$ & 0,86 & - \\
E/P4S2 & $\hat{\mathrm{Y}}=9,29-0,0015 \mathrm{X}$ & 0,99 & - \\
E/P5S1 & $\hat{\mathrm{Y}}=87,4-0,054 \mathrm{X}+0,0000089 \mathrm{X}^{2}$ & 3034 \\
E/P5S2 & $\hat{\mathrm{Y}}=7,39-0,00095 \mathrm{X}$ & 0,99 & -
\end{tabular}

$\mathrm{P} 1-18 \%$ de proteína bruta $(P 1=18 \%$ of crude protein).

P2 $-20 \%$ de proteína bruta $(P 2=20 \%$ of crude protein).

P3 - $22 \%$ de proteína bruta $(P 3=22 \%$ of crude protein)

P4 $-24 \%$ de proteína bruta ( $P 4=24 \%$ of crude protein).

P5 $-26 \%$ de proteína bruta ( $P 5=26 \%$ of crude protein).

S1 - Fêmeas (S1 - Females).

S2 - Machos (S2 - Males).

Tabela 14 - Médias da conversão alimentar acumulada em fêmeas e machos de codornas Japonesas, referentes a cada combinação proteína bruta e energia metabolizável (EM)

Table 14 - Female and male Japanese quails total feed:gain ratio average for each crude protein and metabolizable energy (ME) combination

\begin{tabular}{|c|c|c|c|c|c|c|}
\hline \multirow[t]{2}{*}{$\begin{array}{l}\text { Sexo } \\
\text { Sex }\end{array}$} & \multirow[t]{2}{*}{$\begin{array}{l}\mathrm{EM}(\mathrm{kcal} / \mathrm{kg}) \\
M E(k c a l / k g)\end{array}$} & \multicolumn{5}{|c|}{$\begin{array}{c}\text { Níveis de proteína bruta }(\%) \\
\text { Crude protein levels }(\%)\end{array}$} \\
\hline & & 18 & 20 & 22 & 24 & 26 \\
\hline $\begin{array}{l}\text { Fêmeas } \\
\text { Females }\end{array}$ & 2800 & $4,57^{*}$ & $4,15^{*}$ & $4,35^{*}$ & $4,52^{*}$ & $4,63^{\mathrm{NS}}$ \\
\hline $\begin{array}{l}\text { Machos } \\
\text { Males }\end{array}$ & & 4,98 & 5,14 & 5,11 & 4,99 & 4,71 \\
\hline $\begin{array}{l}\text { Fêmeas } \\
\text { Females }\end{array}$ & 3000 & $4,23^{\mathrm{NS}}$ & $4,07^{*}$ & $4,13^{*}$ & $4,07^{*}$ & $4,06^{*}$ \\
\hline $\begin{array}{l}\text { Machos } \\
\text { Males }\end{array}$ & & 4,45 & 4,70 & 4,68 & 4,64 & 4,53 \\
\hline $\begin{array}{l}\text { Fêmeas } \\
\text { Females }\end{array}$ & 3200 & $3,86^{*}$ & $3,92^{*}$ & $3,73^{*}$ & $3,99 *$ & $4,20^{\mathrm{NS}}$ \\
\hline $\begin{array}{l}\text { Machos } \\
\text { Males }\end{array}$ & & 4,56 & 4,50 & 4,33 & 4,38 & 4,32 \\
\hline
\end{tabular}

* Significativo pelo teste $\mathrm{F}$ em nível de $5 \%$ de probabilidade.

NS - Não significativo $(P>0,05)$.

* Significant by $\mathrm{F}$ test for probability level of $5 \%$.

NS Not significant $(P>$.05).

\section{Conclusões}

As exigências estimadas de proteína bruta (PB) e energia metabolizável (EM), durante o primeiro (5 a 16), terceiro (27 a 38 ) e quarto (38 a 49 dias de idade) períodos, foram: 26 e 2800, 18 e 3200 e $19,62 \%$ e $3200 \mathrm{kcal} / \mathrm{kg}$ ração para fêmeas e 26 e
2800,18 e 3200 e $18 \%$ e $3200 \mathrm{kcal} / \mathrm{kg}$ ração para machos, respectivamente.

A exigência de PB estimada para fêmeas e machos no segundo período ( 16 a 27 dias de idade) foi de $26 \%$, entretanto não foi possível estimar a exigência de EM para ambos os sexos.

No período total (5 a 49 dias de idade), a exigência 
protéica, estimada para máximos ganhos de peso acumulados de fêmeas e machos, foi de $24,73 \%$, sendo que não foi possível estabelecer a exigência energética de ambos os sexos.

As idades estimadas que resultaram em peso (P) máximo foram dependentes do nível de $\mathrm{PB}$ da dieta e, por isso, variaram entre 91 e 189 e 57 e 83 dias para fêmeas e machos, respectivamente.

Codornas machos alimentadas com dietas com níveis protéicos mais elevados tiveram maior redução no número de dias em que ocorreu $\mathrm{P}$ máximo, independentemente do nível energético.

\section{Literatura Citada}

ANGULO, E.; BRUFAU, J.; MIQUEL, A. et al. Effect of diet density and pelleting on productive parameters of Japanese quail. Poultry Science, v.72, p.607-610, 1993.

BEGIN, J.J. A Comparison of the ability of the Japanese quail and light breed chicken to metabolize and utilize energy. Poultry Science, v.47, p.1278-1281, 1968.

DU PREEZ, J.J.; SALES, J. Growth rate of different sexes of the European quail (Coturnix coturnix). British Poultry Science, v.38, p.314-315, 1997.

FARRELL, D.J; ATMAMIHARDJA, S.I.; PYM, R.A.E. Calorimetric measurements of the energy and nitrogen metabolism of Japanese quail. British Poultry Science, v.23, n.5, p.375-382, 1982.

HYÁNKOVA, L.; DEDKOVÁ, L.; KNÍZETOVÁ, H. et al. Responses in growth, food intake and food conversion efficiency to different dietary protein concentrations in meat-type lines of Japanese quail. British Poultry Science, v.38, p.564-570, 1997.

KIRKPINAR, F.; OGUZ, I. Influence of various dietary protein levels on carcass composition in the male Japanese quail (Coturnix coturnix japonica). British Poultry Science, v.36, p.605-610, 1995
MARKS, H.L. Compensatory growth in Japanese quail following protein restriction. Poultry Science, v.57, p.1473-1477, 1978 .

MURAKAMI, A.E.; MORAES, V.M.B.; ARIKI, J. et al. Níveis de proteína e energia em rações para codornas Japonesas (Coturnix coturnix japonica) em crescimento. Revista da Sociedade Brasileira de Zootecnia, v.22, n.4, p.534-540, 1993.

NATIONAL RESEARCH COUNCIL - NRC. Nutrient requirements of poultry. 9.rev.ed. Washington, D.C.: 1994. $155 \mathrm{p}$.

ROSTAGNO, H.S.; SILVA, D.J.; COSTA, P.M.A. et al. Composição de alimentos e exigências nutricionais de aves e suínos (Tabelas Brasileiras). Viçosa: Universidade Federal de Viçosa, 1994. 59p.

SHIM, K.F.; VOHRA, P. A review of the nutrition of Japanese quail. World's Poultry Science Journal, v.40, n.3, p.261-274, 1984.

SINHA, R.R.P.; VERMA, A.K. Effect of different levels of dietary protein in Japanese quail (Coturnix coturnix japonica) feeding. Indian Journal of Animal Health, v.23, n.1, p.77-80, 1984.

UNIVERSIDADE FEDERAL DE VIÇOSA - UFV. SAEG Sistema de análises estatísticas e genéticas. Versão 7.1. Viçosa, MG: 1997. 150p. (Manual do usuário).

VOHRA, P. A review of the nutrition of Japanese quail. World's Poultry Science Journal, v.27, n.1, p.26-34, 1971. 